\title{
- que se valoriza na matemática escolar: refletindo sobre as mudanças necessárias
}

\author{
Celia Finck Brandt ${ }^{1}$
}

\begin{abstract}
RESUMO
Ao refletir sobre o mundo-vida constituído pela escola, professores, alunos e o trabalho com a matemática, onde tem se dado minha existência, atuando há quinze anos como professora de matemática, compreendi que a escola não tem dado conta de consolidar a educação matemática de qualidade que se faz necessária. Compreendendo que o fracasso do aluno em matemática é acima de tudo o fracasso da escola em dar conta do processo de ensino-aprendizagem da matemática, Aponto como caminho a investigação da natureza das respostas erradas apresentadas pelos alunos às diversas questões-problemas a eles propostos em diversas situações no ambiente de sala de aula. Assim, as respostas apresentadas pelos alunos em testes, provas, atividades ou situações de sala de aula podem ser analisadas, buscando através da descrição/interpretação, a compreensão das causas dos erros identificados. A interpretação/compreensão fez emergir elementos relacionados aos procedimentos metodológicos adotados e ao domínio do conteúdo pelo professor, como possíveis causas dos erros dos alunos. As análises das observações possíveis em relação ao fenômeno situado, busca aproximar-se de respostas, a respeito da importância de uma prática de avaliação centrada na negociação das respostas apresentadas pelos alunos como possibilitadora de construções de significados em relação à matemática.
\end{abstract}

Palavras-chave: matemática, educação matemática, erro matemático

\footnotetext{
${ }^{1}$ Professora Assistente I da Universidade Estadual de Ponta Grossa, do Departamento de Métodos e Técnicas de Ensino da Disciplina de Metodologia e Prática de Ensino em Matemática do Curso de Licenciatura em Matemática.Professora de matemática para o $1^{\circ}$ e $2^{\circ}$ graus da Rede Estadual de Ensino.

Olhar de professor, Ponta Grossa, 1(1):75-90, out. 1998.
} 
O processo de ensino-aprendizagem da matemática, da forma como se concretiza na realidade escolar, pública ou particular, nos diversos graus de ensino, $1^{\circ}, 2^{\circ}$ ou $3^{\circ}$ graus, tem se revelado ineficaz e inadequado. Vários são os fatores que evidenciam esta ineficácia, apontados por estudos e pesquisas, além dos altos índices de evasão e repetência dos alunos nesta disciplina.

Os indicadores mais fortemente percebidos, tanto pelos professores que lecionam essa disciplina como pelos que lecionam outras que requisitam os conhecimentos matemáticos, referem-se a: os alunos não apreendem os conceitos ao longo da escolaridade (identificados pela falta de prérequisitos ou pela demonstração da não compreensão dos conceitos básicos e fundamentais); os alunos são mais hábeis em seguir regras ou modelos do que em explicar ou justificar os procedimentos adotados na resolução das questões propostas; a ênfase dada ao domínio dos algoritmos pelos professores, em detrimento das compreensões; a não valorização dos cálculos mentais em decorrência das formas de avaliação, baseadas em itens de testes ou provas, sem análise das estruturas mentais requisitadas; a não transferência e não identificação dos conhecimentos matemáticos em outras situações (outra área de conhecimento, situações de vida e outros) e a grande aversão pela matemática ou dificuldade para compreendê-la, caracterizadas pelos sentimentos de desprazer ou ansiedade.

A minha prática em sala de aula com alunos do $2^{\circ}$ grau e de $5^{\text {a }}$ a $8^{\text {a }}$ séries do $1^{\circ}$ grau, durante 15 anos, permitiu o confronto com situações de erros cometidos pelos alunos em questões matemáticas, que levam a acreditar no fracasso da escola em dar conta desse processo.

Pode-se afirmar que qualquer professor, ao se deparar com o processo de ensino-aprendizagem da matemática, principalmente no $1^{\circ}$ e $2^{\circ}$ graus, já identificou questões como estas:

a) $\frac{1}{2}+\frac{1}{3}=\frac{2}{5}$

b) $\frac{2}{3} \times \frac{3}{5}=\frac{10}{9}$ ou $\frac{1}{2}: \frac{1}{5}=\frac{2}{1} \times \frac{5}{1}=10$

ou $\frac{1}{2}: \frac{2}{5}=\frac{1}{5}$

c) $(a+b)^{2}=a^{2}+b^{2}$

d) $x \cdot x=2 x$

e) $4 \times 0=4$

f) $2^{3}=6$

g) $20 \times 30=60$

h) $-2+3=-1$

i) $412: 4=13$

Poderíamos ainda enumerar uma infinidade de erros comuns ao grupo de alunos em testes, provas, trabalhos ou exercícios. Esses erros refletem uma atitude arraigada no aluno de seguir regras práticas e, se indagado a respeito de suas conclusões errôneas, constanten ente afirma á: 


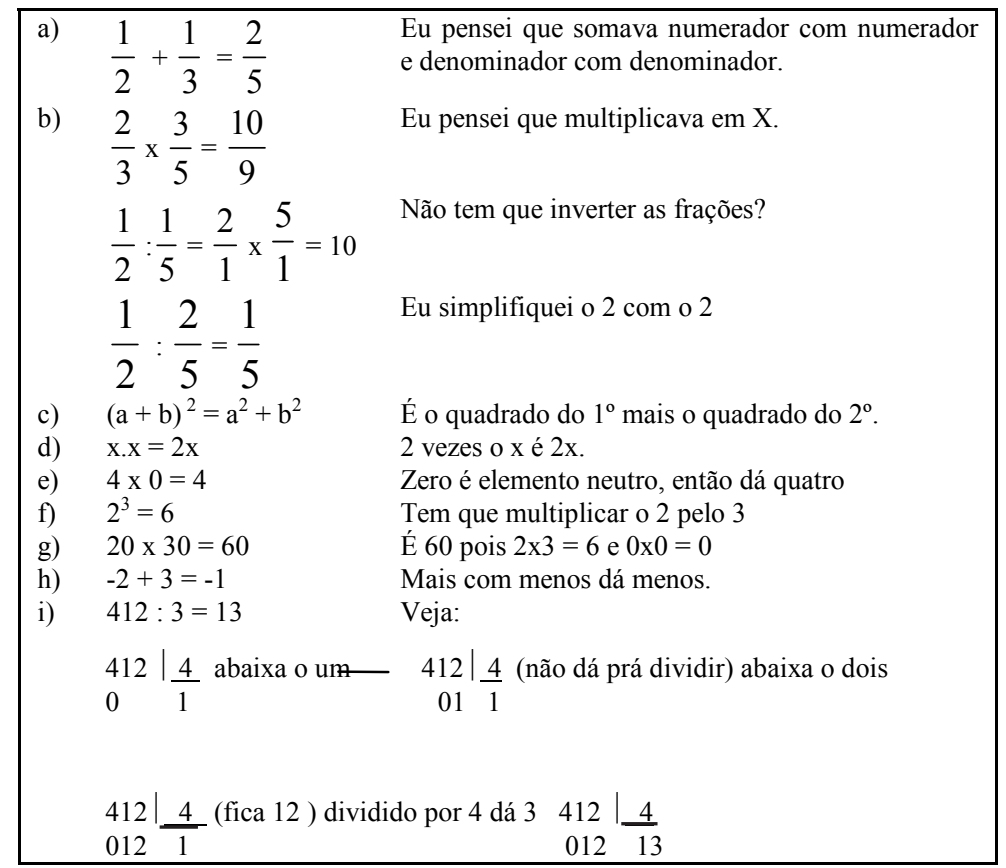

Numa investigação realizada por nós, com a participação das alunas do curso de Magistério do Instituto de Educação do Paraná, apresentada na Feira de Ciências da escola no ano letivo de 1992, que pretendia verificar a real compreensão por parte dos alunos do Sistema de Numeração Decimal, foram propostas algumas situações:

Situação 1: Por que ao multiplicar 12 por 13 afastamos uma casa?

$$
\begin{array}{r}
12 \\
\times 13 \\
\hline 36 \\
12 \\
\hline
\end{array}
$$

Situação 2: Posso dividir 416 por 4 começando pela casa das unidades? Respostas obtidas: Não pode. Não vai dar certo. Tem que começar pelo outro lado.

Esta mesma questão foi proposta em vários cursos para professores $\mathrm{e}$ após a resolução, causou polêmica e até mesmo rejeição a este procedimento. O procedimento utilizado foi:

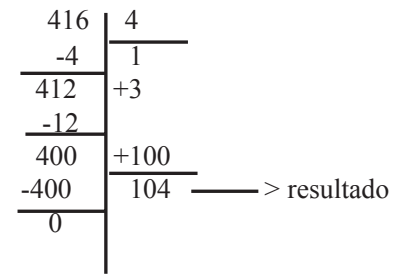


Argumentos utilizados: Assim complica muito. As crianças não vão entender, pois é mais difícil.

Muitos professores parecem resistir aos questionamentos impostos pelos algoritmos. Se levados a investigar o porquê da rigidez das regras, concluem a priori que outras abordagens dificultariam a compreensão (nesse caso não percebida como repetição). Justificam que foi assim que "aprenderam" e é assim que sabem ensinar. A flexibilidade dos algoritmos não é questionada. Ao perguntar aos professores por que, na divisão de frações, invertem a segunda fração e transformam em multiplicação, ou em que contexto podemos descrever a situação $1 / 2: 2=4$, afirmam nunca terem pensado sobre isto ou consideram que esta regra de inverter a segunda fração é e sempre foi assim por algum motivo que julgam não precisar conhecer para compreender. Os professores aceitam as regras e as transmitem, como se este fosse o único caminho a ser percorrido para a proposta do ensino da matemática.

A valorização aos procedimentos por escrito pela escola não encontra base sólida em seus argumentos de defesa e é inerentemente inferior aos procedimentos baseados em cálculos mentais ou em processos naturais.

Os resultados de CARRAHER et al. (1989) apontaram que "a combinação do método etnográfico com o método clínico piagetiano ${ }^{1}$ mostrou-se especialmente adequada na descoberta da competência numérica das crianças que, em contextos mais próximos do escolar, apresentam rendimento insatisfatório" (CARRAHER et al., 1989, p. 41).

Seu estudo apontou que o recurso às heurísticas de decomposição ou agrupamento repetido permite à criança manipular quantidades em valores que podem ser mais facilmente trabalhados. O recurso ao lápis e papel ocorria devido à sobrecarga de memória. A preferência recaiu no trabalho com as centenas, depois dezenas e por último unidades, novamente derrubando a rigidez dos algoritmos. Quando das quantidades que envolviam zeros, os procedimentos mentais ou orais tornaram-se mais fáceis que os escritos. Segundo a au-

\footnotetext{
${ }^{1}$ CARRAHER et al. apresentam uma coletânea de estudos compreendendo uma investigação de atividades cotidianas, dentro e fora da escola. A abordagem metodológica aproxima-se do método clínico piagetiano onde o investigador procurou descobrir, através da obtenção de justificativas e da apresentação de novos problemas, que formas de raciocínio o sujeito estava utilizando, interferindo diretamente no desenrolar dos acontecimentos, propondo questões sucessivas. $\mathrm{O}$ instrumento de coleta de dados foi uma entrevista não baseada em um roteiro inflexível, porém relativa à um mesmo objeto matemático. A metodologia utilizada em tal estudo, que combina o método etnográfico com o método clínico piagetiano, permitiu constatar ser possível explorar mais amplamente as habilidades demonstradas pelas crianças, tanto no contexto da escola como em contextos naturais. Permitiu também esclarecer os processos através dos quais a criança adquire a compreensão do sistema numérico, o que a faz operar eficazmente em contextos naturais.
} 
tora o excesso de valorização aos procedimentos escritos parece conduzir à perda do significado das transações que estão sendo quantificadas, assim como o significado dos algarismos dentro dos sistemas de quantificações.

Não se pretende afirmar que devemos substituir um procedimento por outro, mas que devemos valorizar mais uma dosagem maior e mais significativa dos procedimentos orais e do cálculo mental, durante os processos de avaliação. Precisamos permitir que o aluno possa confrontar a sua forma de pensar com o procedimento escrito, pois este procedimento pode ser a ponte necessária para o resgate de questões relacionadas à compreensão e apreensão dos conceitos matemáticos. Desmistificará a questão de que existem formas aparentemente mais apropriadas do que outras em matemática.

Muitas pesquisas compreendendo a educação matemática ou situações envolvendo a prática educativa nas escolas com a matemática, revelam situações específicas que devem ser analisadas, visto a importância e sig- nificado para o alcance da educação matemática de qualidade.

Fatos ocorridos com grupos de alunos fora do ambiente escolar foram objeto de investigação de um grupo de pesquisadores de Pernambuco. CARRAHER et al. (1989) relatam situações específicas que permitem claramente identificar o quanto as heurísticas de pensamento afastam-se dos procedimentos escritos, tão valorizados pela escola. Ao propor a um sujeito qual o troco a ser dado para o pagamento de um coco que custava 35 , se lhe fosse dada uma nota de 200 , obteve como resposta 165. Ao indagar o porquê, obtém do sujeito uma resposta, cujo procedimento caracteriza-se por apresentar uma heurística de decomposição. O sujeito lhe responde: Se fosse 30 seria 70, então é 65,165 . Analisando a resposta percebeu-se que em frações de segundos o sujeito fez decomposições e arranjos que lhe permitiram alcançar o resultado e, ao mesmo tempo, o quanto este procedimento mental afasta-se dos algoritmos:

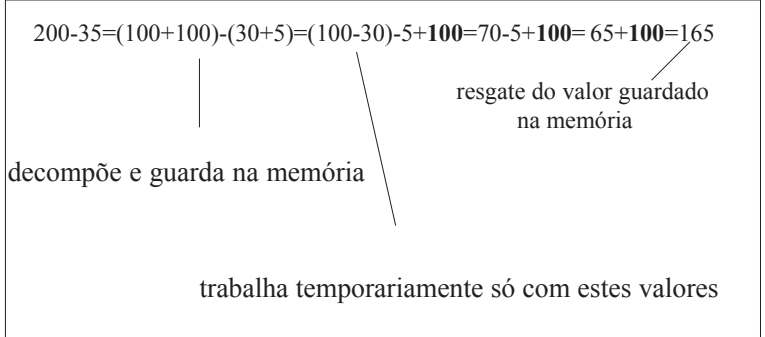


Se este procedimento fosse permitido quando da utilização do algoritmo, ficaria assim:

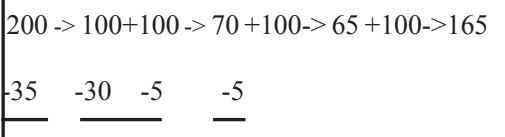

O que ficou registrado claramente para a autora é que para a maioria dos sujeitos envolvidos na pesquisa, a matemática da escola, escrita com lápis e papel, tem pouco ou nada a ver com a matemática construída e pensada. Os sujeitos da pesquisa deixaram claro aos pesquisadores que o modo natural de fazer contas é $\boldsymbol{n a}$ cabeça. Os sujeitos envolvidos deixaram claro acreditar que nesta matemática (da escola) as coisas acontecem estranha e magicamente e os resultados obtidos podem, por sorte ou acaso, estarem corretos. Outras situações também foram investigadas e apontaram para as mesmas conclusões.

KAMII (1985) ao propor a uma criança o problema: "Você tem 7 flores e me dá 3, com quantas fica?" recebeu a resposta 7 . Ao indagar o porquê da afirmação recebeu a seguinte explicação: Se tenho 7 flores e te dou 3 ainda fico com 7. Ao separar as 3 flores solicitadas não as retirou do seu grupo de 7. Num processo corriqueiro de avaliação essa resposta seria simplesmente considerada errada, quando, em essência, do ponto de vista lógico, está correta, em virtude de que o problema permitiu a interpretação dada pela criança.

FRAGA (1988) também descreve um diálogo entre professor e alunos que mais uma vez evidencia as questões até aqui tratadas. $O$ professor reúne 4 alunos, cerca-os com uma corda e pergunta: "Como se chama cada aluno do conjuntinho?" Uma criança responde alimento em vez de elemento. Numa outra situação o mesmo professor apresenta a adição como inimiga da subtração. Além da distorção semântica e matemática, proceder desta forma significa transmitir ao aluno um conceito confuso. Quanto às respostas erradas o professor diz que o aluno não prestou atenção e por isto não aprendeu.

As situações descritas são indicadores de que a escola não investiga a lógica dos alunos quando da apresentação de respostas e aceita que devemos ensinar aos alunos as operações isoladas de qualquer contexto, para depois apresentar as mesmas operações no contexto de problemas.

Os resultados apontados na pesquisa de CARRAHER et al. (1989) confrontam essa noção implícita, mostrando que a análise lógica implicada na solução de um problema facilita a realização da operação, por inseri-la num sistema de significados bem compreendidos, ao invés de constituir uma habilidade isolada.

[...] Essa análise qualitativa dos 
resultados sugere que os algoritmos ensinados na escola para a realização de operações aritméticas podem constituir um obstáculo ao raciocínio da criança, talvez por interferir com o significado dos próprios números com os quais a criança deve operar. (CARRAHER et al., 1989, p.35-36)

Apesar das múltiplas lógicas corretas utilizadas para a resolução de problemas, a escola valoriza um único tipo de procedimento, transmite a idéia de que existe uma única forma de proceder que poderia levar ao resultado e não aproveita os procedimentos naturais ou inventados. Não considera possível que o aluno "adquira fluência nos métodos informais de decomposições, sem dominar os métodos escolares (regras de vai um; multiplicação feita por escrito, começando-se com a casa das unidades; colocação convencional de números no papel etc.)". (CARRAHER et al., 1989, p.39)

A atitude ou postura atual da escola reflete uma ideologia que desvaloriza o saber popular e não deixa que este tenha lugar na escola e nem é reconhecido num sistema de promoção. Isto pode significar ser "importante reconhecer na etnomatemática um programa de pesquisa que caminha juntamente com a prática escolar. [...] Do ponto de vista conceitual etnomatemática significa a arte ou técnica de explicar, de conhecer, de entender nos diversos contextos culturais" (D’AMBRósIo, 1980, p. 5-6). O homem encontrou e sempre encontrará formas próprias de explicar a realidade a ele sensível. Grupos culturais distintos apresentam diferenças que envolvem posturas conceituais e enfoques cognitivos distintos. Considerando que possamos admitir que a "atividade humana resulta de motivação proposta pela realidade na qual está inserido o indivíduo através de situações ou problemas que essa realidade lhe propõe" (D’AMBRÓsIo,1980, p. 6-7), precisamos compreender que a valorização a processos artificializados podem conduzir a percepções e compreensões errôneas.

BURIASCO (1988, p. 1), em estudo apresentado que compreendeu entrevistas com crianças que nunca haviam freqüentado a escola, revela que "a criança, antes do início de sua escolarização, já possui meios de lidar com problemas quantitativos. Esses meios, que não envolvem obrigatoriamente a contagem, são algumas vezes ineficazes, outras vezes elementares e outros ainda, surpreendentemente sofisticados". A procura para descobrir qual o conhecimento que a criança tem de matemática antes de entrar na escola permitiu à autora a tradução das descobertas geradas e revelou que a matemática não é aprendida pela criança só após entrar na escola, a partir de um ensino sistemático pelo professor. Isto significa não ser possível admitir a hipótese de que a criança só começa a classificar e ordenar os objetos do seu mundo a partir de ordens recebidas pela esco- 
la. A criança recebe informações as mais variadas do mundo em que vive, dos pais, das pessoas com as quais convive e, ao chegar à escola é considerada tábula rasa, recebendo uma variedade de informações desarticuladas da realidade. Repetem, por exemplo, seqüências numéricas para "aprender" número, como se este pudesse ser ensinado. A criança é obrigada a ignorar tudo o que sabe sobre a matemática para seguir um código gráfico padrão. Seus estudos revelaram ser possível ao professor um caminho de como trazer essa etnomate-mática para dentro da escola, passando do bloqueio à transição, sendo assim possível perceber suas intuições primeiras, informais e originais e, a partir destas, iniciar o trabalho em sala de aula.

Foi desta forma que BURIASCO (1988) conseguiu perceber a forma pela qual alguns temas de matemática, presentes nos programas de $1^{\mathrm{a}}$ série, são conhecidos pelas crianças que entrevistou. Será interessante relatar al- guns pela riqueza de detalhes e seus significados. É o caso, por exemplo, de: noção de meio e metade, percebidos de formas diferentes quando de quantidades contínuas ou discretas; noções de altura, também percebida de forma diferente quando associada à contagem ou ao espaço topológico ou mesmo de registros de quantidades quando do não conhecimento do sistema de numeração posicional decimal.

A noção de meio e metade já é uma noção bem clara mas não é exatamente como é passada na escola. Segundo elas, as metades tem que ser iguais ou ter a mesma quantidade. [...] Mesma quantidade elas usavam para o que podiam contar [...] e igual para o que não podiam. [...] 'metade é cada lado do meio'e 'meio é onde divide na metade'. (BURIASCO, 1988, p.51).

Assim, segundo Buriasco (1988, p. 52):

Para quantidades discretas
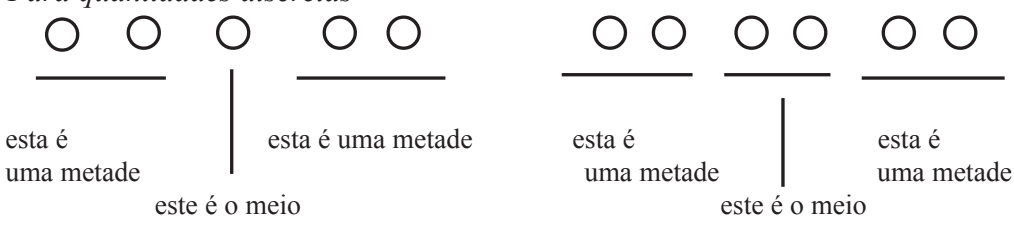

Para quantidades contínuas
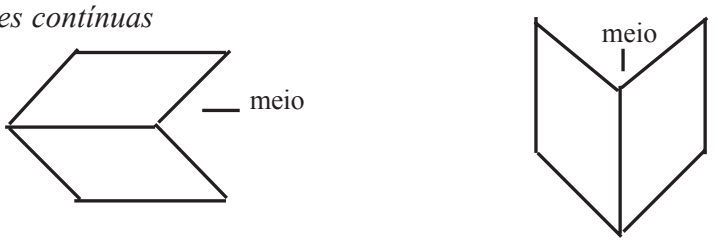
Em relação ao espaço topológico, para a criança, o que se poderia colocar no meio de uma sala é só uma folha de papel, pois qualquer outra coisa passaria do meio.

"Esta não é exatamente a idéia de meio e metade trabalhada na escola. Parece que para as crianças a noção é geométrica e a da escola aritmética, uma vez que para aquelas o meio é o 'onde' que separa as metades e estas são 'aquilo que' é separado pelo meio" (BURIASCO, 1988, p.53).

Ainda em relação aos resultados apresentados por BURIASCO (1988), interessante será relatar o registro de quantidades por uma das crianças que ainda não dominava o sistema de numeração decimal posicional para representação de quantidades. Para representar 13 peças contadas, escreveu 811111, o que mostrou o seu domínio de um aspecto importante do conceito de número, já então por ela construído, que é a adição de mais um.

Se analisadas, as respostas das crianças surpreendem pela lógica utilizada. É o caso por exemplo de afirmações de algumas crianças: muitas flores num vaso vai depender do tamanho do vaso; "zero" não é pouco, é nada, e que para ter bem pouco é preciso pelo menos ter um; é possível obter-se a metade de uma bolinha de gude, porém isto seria sem sentido, pois, ao parti-la, não se poderia mais jogar com ela. Estas percepções reveladas no estudo de BURIASCO (1988) indicam o quão importante é o diálogo com as crianças e a análise de suas respostas.
As questões matemáticas apresentadas pela escola podem distanciarse de tal modo da compreensão do aluno e de sua lógica que o levam, com o tempo, a sentir aversão ou indiferença pela matemática.

Através do diálogo com os alunos, pode-se sempre desvelar algo novo. Os padrões adotados pela escola são rígidos em relação aos processos naturais de pensar, perceber e representar os conceitos matemáticos. Essa questão precisa ser revista e analisa$\mathrm{da}$, pois pode representar um dos fatores de evasão e repetência dos alunos nas escolas de $1^{\circ}$ e $2^{\circ}$ graus.

Estes inúmeros fatos comprovam que o fracasso do aluno em matemática revela o fracasso da escola em trabalhar e propor a matemática aos alunos.

A escola, impõe prematuramente os algoritmos, valoriza a repetição de modelos ou padrões, através de memorizações ou reproduções, e não considera as noções já concebidas pelos alunos, mesmo que não sistematizadas, não valorizando os conhecimentos lógico-matemáticos usados na prática social. Sempre propõe os conceitos matemáticos como se não houvesse concepção prévia, fruto dos estímulos fornecidos pelo meio ambiente e sociedade. Esse tratamento é característico de qualquer grau de ensino: pré-escola, primeiro, segundo ou terceiro graus.

O aluno, por sua vez, ao depararse com regras e modelos que não expressam as heurísticas mentais tenta, 
com grande esforço, adaptar-se a essa situação estranha e confusa, dando respostas que podem ser consideradas normais, posto o que lhe é exigido. Sabe que tem que fazer alguma coisa, seguir alguma regra, mas nunca é incentivado a fazer leituras ou análises.

O professor, por sua vez, no processo de avaliação, sem perceber, reforça essa atitude, ao considerar simplesmente CERTO ou ERRADO, por não investigar com o aluno a natureza do seu erro, por não perguntar a ele como pensou ou o porquê daquela resposta, por não refletir sobre os procedimentos metodológicos adotados, por não analisar a natureza dos itens de teste em consonância com os processos mentais e por não distinguir erros em virtude de pré-requisitos ou do conteúdo matemático envolvido.

O processo de ensino-aprendizagem da matemática, da forma como é proposto nas escolas, também precisa ser analisado sob a ótica da democratização do ensino, que implica na apropriação/transmissão do saber elaborado e sistematizado.

Como conseqüência, a ação docente concretizada no âmbito da sala de aula e manifestada pelas atitudes dos professores em consolidar práticas inadequadas precisa ser refletida sob a ótica do papel político do professor face a essa democratização.

A ênfase demasiada nos registros por escrito é uma atividade que se pratica da mesma forma que as atitudes e valores relativos ao que é apropriado em matemática.

Esta ideologia não apenas inibe o cálculo oral, mas também desvaloriza este tipo de saber popular, que não tem lugar na escola nem pode ser reconhecido num sistema de promoção em que todas as avaliações são feitas por escrito. Quando constatamos que a escola rejeita esse saber popular da criança, manifesto na matemática oral, precisamos perguntar: a quem interessa esta rejeição? Ao aluno? Ao professor? A sociedade? (CARRAHER et al., 1989, p. 66).

A escola tem a função específica da apropriação do saber sistematizado e pode tornar o saber socializado se oportunizar a compreensão dos conceitos e não a simples reprodução de uma ciência pronta e acabada.

Apesar de os mecanismos institucionais governamentais não contribuírem para esta socialização, refletidos mais intensamente na desvalorização do professor, acredito que o espaço da sala é um dos únicos de intensa liberdade. Nele, apesar dos mecanismos da seletividade, ainda se pode concretizar a socialização do saber.

O fardo é pesado, porém não impossível para o professor. Imputar-lhe tal responsabilidade não significa atribuir-lhe a tarefa, mas despertá-lo para a sua força quando compromissado e consciente do papel a cumprir.

É nessa escola que existe a matemática como saber sistematizado para ser ensinada em um momento defini- 
do por alguém de maior competência: o professor.

A matemática é parte da vida de um sujeito e todo corpo de conhecimentos matemáticos foi construído pelos homens a partir das necessidades práticas e possibilidades teóricas. Como é possível que a matemática vista e aprendida na escola possa estar tão descontextualizada da vida das pessoas? Como pode a matemática ser um dos mecanismos de seletividade, um filtro social, capaz de privilegiar alguns, considerados "bem dotados" do sistema escolar?

Atribuir o fracasso escolar ao aluno, ao professor, às Secretarias de Educação ou às Universidades não responde à questão, pois:

A criança que aprende matemática na rua, o cambista analfabeto que recolhe apostas, o mestrede-obras treinado por seu pai todos eles são exemplos de que nossas análises estão incompletas, precisam ser desmanchadas e refeitas, se quisermos criar a verdadeira escola aberta a todos [...]. Precisamos não encontrar os culpados, mas as formas eficientes do ensino aprendizagem em nossa sociedade (CARRAHER et al.,1989, p. 21).

Uma reflexão acerca do processo ensino-aprendizagem contemporâneo da matemática nas escolas de primeiro, segundo e terceiros graus deve compreender as concepções subjacentes à prática pedagógica e ao discurso do professor. E estas concep- ções, por sua vez, compreendem dimensões: epistemológica, teleológicaaxiológica, psicológica e didáticometodológica.

A prática observada, se analisada sob a dimensão epistemológica, vem "transformando essa forma de saber em ciência do anti-logos, com toda incongruência que a expressão 'ciência da negação da razão' possa suscitar" (MIGUEL, 1994, p.53).

Se analisada sob a dimensão teleológica-axiológica,

a prática em questão caracteriza-se pela neutralidade e descompromisso em relação aos problemas e anseios da sociedade.[...] Ao valorizar o conteúdo pelo conteúdo, consolida uma prática de elos intermináveis que vai do nada a lugar nenhum, descaracteriza o significado e o sentido do conhecimento matemático, [...] gerando nos estudantes a sensação de que o único sentido de um ato está no próprio ato" (MIGUEL, 1994, p.54).

Sob a dimensão psicológica, a prática pedagógica caracteriza-se por uma relação cognitiva segundo a qual o sujeito é passivo, receptivo e contemplativo. É uma concepção que se caracteriza pelo sensualismoempirismo.

$\mathrm{Na}$ dimensão didático-metodológica, predomina

[...] te tecnicismo que privilegia os métodos capazes de transmitir os conteúdos não contextualizados. Conteúdos livres de contradições 
e desligados de problematizações. [...] A concepção mecanicista do método não ouve. Expõe. Não pergunta. Responde. Não dialoga, não levanta e analisa contradições não acredita que o significado de uma idéia só seja acessível na medida em que aparece sobre um fundo de erros mais profundos, isto é, na medida em que essa idéia interage com outros que já participam dos diferentes campos semânticos construídos diferentemente por cada aprendiz (MIGUEL, 1994, p. 54)

O desafio que se impõe hoje é a emergência da derrubada desse paradigma de educação matemática, que em nada contribui para o preparo do cidadão para uma vida política e social baseada na convivência plural democrática. Preparo que inclui a formação dos indivíduos para "pensar de forma independente, criativa e críti$\mathrm{ca}$, aplicando esse pensamento para o aperfeiçoamento da democracia, para a preservação da vida, para melhoria das condições materiais e espirituais de existências e para a restituição da dignidade de todos os seres humanos" (MIGUEL, 1994, p. 60).

Isto significa que um novo paradigma para a educação matemática se impõe como necessário e emergente. Neste contexto, a educação matemática deve promover nos alunos a compreensão dos significados, estrutura e função dos conceitos matemáticos. Para tanto, deve promover mudanças reais no ensino tradicional, as quais compreenderão transformações profundas em relação às concepções epistemológicas, psicológicas e pedagógicas do professor e a prática de sala de aula.

A escola, o professor, a sala de aula, a função política do professor e a sua formação devem ser refletidas à luz do paradigma emergente que seja capaz de consolidar uma prática eficaz em relação à educação matemática de qualidade.

\section{Considerações finais}

O caminho que pode ser sugerido é uma abordagem voltada para as respostas dadas pelos alunos em sala de aula, atividades ou para os erros apresentados permitem identificar os elementos e as questões que permeiam a Educação, a sala de aula e o fazer do professor em contextos específicos e contextualizados.

Desta forma, a situação dialógica que se estabelece do professor com seus alunos, do professor consigo mesmo e do aluno consigo mesmo pode permitir identificar os diversos níveis em que se encontram as compreensões dos objetos matemáticos. Silêncios, dúvidas e ansiedades podem ser ouvidos e trabalhados.

Esta abordagem deve permear toda a prática pedagógica em todos os graus de ensino. Isto significa estarmos admitindo uma prática pedagógica centrada nas respostas dos alunos com possibilidades, análises e 
reflexões sobre as causas dos erros apresentados.

O movimento dialético que se estabelece permite a cada momento descrições, interpretações/compreensões dos elementos uma nova organização / reorganização da ação pedagógica.

As descrições/interpretações das respostas permitem a identificação dos elementos significativos a partir da compreensão. Estes elementos passam por análises, reflexões e reformulações que se fizerem necessárias e podem surgir novamente com outras especificidades em outros contextos.

$\mathrm{O}$ que se pretende afirmar é que os erros dos alunos em matemática podem e devem ser os elementos de orientação e reorganização da prática educativa, pois poderão sempre revelar os elementos a serem considerados em cada momento, em cada situação de sala de aula, com cada grupo de alunos ou um aluno em particular e a cada conceito matemático com suas especificidades.

As possibilidades, análises e reflexões que tal abordagem oferece, pode ser um caminho para aqueles que procuram uma educação matemática de qualidade e significativa para o aluno de hoje, preparando-o como cidadão do futuro que hoje se faz presente.

Durante três anos consecutivos venho desenvolvendo esta prática educativa analisando em cada teste, atividade, prova ou situações de sala de aula as respostas apresentadas pelos alunos e os erros identificados.
Desta forma pude compreender melhor os elementos que se mostravam obscuros e de difícil compreensão. Até então não sabia afirmar com certeza se estava ocorrendo a construção de significados pelos alunos, se esta proposta estava sendo significativa em termos de uma educação matemática de qualidade e eficaz, se este modelo estava reproduzindo as relações hegemônicas existente na sociedade por trabalhar com uma ciência elaborada e sistematizada a qualquer grupo, independentemente de sua origem ou classe social, etc.

Hoje posso compreender melhor e vislumbrar minha prática pedagógica como caminho de busca e não como fórmulas mágicas e infalíveis. Acredito que conduzir a prática educativa centrada nas respostas dos alunos pode permitir aproximar-se do desvelar da realidade e dos sujeitos envolvidos com suas manifestações e formas de relações e representações. Estas compreendem os sentidos das falas matemáticas tal como colocado por SOUZA (1995) que devem ser resgatados para que se estabeleça uma ponte entre o saber elaborado e sistematizado e estas formas de representações. Isto significará tentar compreender os significados destas formas de representação e confrontá-los com o discurso tradicional buscando a validade e significação. Esta busca é feita em parceria por alunos e professor.

Tal forma de proceder e conduzir a prática educativa em matemática requer do professor uma nova postu- 
ra relacionada a de um professoraprendiz que poderá identificar os elementos a serem considerados na organização e reorganização das práticas. Só assim teremos a condição de efetivar uma prática comprometida com as necessidades dos grupos envolvidos na instituição escolar.

Acredito ter caminhado em direção a questão que procura apontar que uma prática educativa centrada nas respostas dos alunos e nos níveis de compreensão, reflexão e autonomia contribui para a apropriação do saber matemático pelos alunos. De fato esta prática possibilita:

- a percepção dos vários níveis em que se encontram as percepções dos objetos matemáticos pelos alunos a caminho da apropriação do saber matemático;

permite:

- a construção de significados pelos alunos e pelo professor;

- a identificação da concepção de matemática pelo professor de sua própria concepção e a dos alunos;

- identificar a concepção de matemática que subjaz aos materiais de apoio e aos procedimentos metodológicos;

- identificar a concepção de educação que subjaz à prática de avaliação,

- e, principalmente permite identificar a coerência evidenciada ou não na ação/discurso revelando toda a sua contradição.

A prática de educação matemática hegemônica caracterizada pela concepção platônica e pelo modelo euclidiano como método para abordagem e apresentação das idéias matemáticas que consolida o fracasso escolar segundo IMENES, (1989), pode ser substituída pela negociação entre o saber contido nas respostas dos alunos e o saber escolar. Desta forma poder-se-á identificar o sentido das falas matemáticas que se revelam no diálogo entre professor e alunos. Este sentido é o discurso que tem que ser percebido e compreendido e deverá ser o critério a partir do qual a prática deve ser organizada. Tal organização considerará sujeitos situados historicamente e temporalmente num meio social e poderá desta forma propor uma educação matemática concreta $\mathrm{e}$ de qualidade, instrumentando os indivíduos com o conhecimento para a conquista de sua liberdade como homem na sua relação com o mundo.

A prática educativa centrada nas respostas dos alunos nos níveis de reflexão, autonomia e compreensão pode permitir o acompanhamento da construção de significados (APRENDIZAGEM) dos objetos matemáticos pelos alunos. O estudo e as análises e reflexões a partir desta abordagem permitem identificar também que esta construção de significados pode se dar também por parte do professor (FORMAÇÃO DO PROFESSOR). Tal abordagem permite ainda verificar os elementos relativos aos procedimentos metodológicos (METODOLOGIA) e como conseqüência aos materiais de apoio, principalmente os livros didáticos. Tais 
análises permitem identificar a concepção de matemática (PARADIGMAS DA EDUCAÇÃO MATEMÁTICA) que subjaz às apresentações dos diversos autores e por esta razão a sua confrontação com as diferentes formas e estratégias para resolução de problemas. Além disso torna possível a identificação das diversas estratégias e heurísticas para obtenção das soluções das questões e problemas apresentados, assim como as dificuldades para identificação dos dados e do exame da solução obtida (Resolução de problemas). Permite também a identificação da natureza dos itens de testes elaborados, a retomada dos erros a partir do diálogo que se estabelece considerando o dito pelos alunos e pelo professor, a compreensão das respostas dadas em relação aos níveis de construção dos objetos matemáticos relativos às simplificações permitidas pelas abstrações mediadoras e a postura do aluno frente ao erro. Todas estas questões compreendem a dinâmica da AVALIAÇÃo como processo pedagógico, que se caracterizou pela percepção das intersubjetividades em tentar apreender subjetivamente as idéias matemáticas, os símbolos e os jargões através do diálogo do saber ouvir e do saber falar. Desta forma, encaminha-se para o desenvolvimento de uma consciência criativa que permite fazer emergir a autonomia do aluno e do professor. Permite também identificar em que momento os símbolos matemáticos e o rigor da LINGUAGEM FORMAL impedem a verificação das reais compre- ensões por parte dos alunos.

Sobre toda a prática educativa tem sido refletido desta forma e muitos outros elementos surgem com suas especificidades que permitem novas reflexões sobre outros aspectos. É uma prática que permite constantemente uma ação que remete a uma reflexão e que gera ação novamente. A mesma dinâmica proposta por D'AMBRósIo (1980) onde existe uma realidade que se manifesta aos indivíduos inseridos num meio, que é social e histórico, que gera ação e por sua vez, reflexão sobre a ação que transforma o indivíduo a partir de suas relações com a realidade e a ela se volta através da ação, e a dinâmica continua.

Assim é a dinâmica da prática centrada nas respostas dos alunos e voltada especificamente para os fins da educação matemática e seu ensino. Em outros ambientes, com outros indivíduos, com outros conteúdos ou objetos matemáticos, com outros professores em outros tempos e lugares com suas particularidades, especificidades e necessidades. É a prática das possibilidades.

\section{REFERÊNCIAS BIBLIOGRÁFICAS}

1 BURIASCO, Regina. Matemática
de fora e de dentro da escola:
do bloqueio à transição. Disser-
tação (Mestrado em Ensino e
Aprendizagem da Matemática e 
seus Fundamentos Filosóficoscientíficos). Curso de Pós-graduação em Educação Matemática, UNESP, 1985.

2 CARRAHER, T.; CARRAHER D.; SHILIEMANN AN, Ana L. Na vida dez, na escola zero. 3 ed. São Paulo: Cortez, 1989.

3 D'AMBRÓSIO, Ubiratan. Etnomatemática. São Paulo: Ática, 1980.

4 FRAGA, Maria Lúcia. A matemática na escola primária: uma observação do cotidiano. São Paulo: EPU, 1988.

5 IMENES, Luiz Márcio. Um estudo sobre o fracasso do ensino e da aprendizagem da matemática. Dissertação (Mestrado em Educação. Matemática). Instituto de Geociências e Ciências Exatas. UNESP, Campus de Rio Claro, 1989.

6 KAMII, Constance. Reinventando a aritmética. Campinas: Papirus, 1985.

7 MIGUEL, Antonio. Reflexão acerca da educação matemática contemporânea. A Educação Matemática em Revista. Blumenau: ano 1, n.2, p.53-60, 1994.

8 SOUZA, Antonio Carlos Carrera et al. Novas diretrizes para a licenciatura em matemática. Temas \& Debates. Blumenau. v.8, n.7, p.41-65, jul. 1995. 